\title{
Cortázar: "que Supo Abrir la Puerta para Ir a Jugar".
}

\section{El Dibujo Del "Mandala"}

Como algunas esculturas modernas consisten en cubos que el espectador puede agrupar a su antojo para apoderarse asi del espacio y reestructurarlo, las obras de Cortázar proponen, con mayor claridad a partir de Rayuela, unos capítulos, fragmentos o a veces simples indicaciones argumentales, para que el lector construya con ellos la novela que quiera leer; para que compongá una nueva realidad. Se busca un lector cómplice, que utilice las pautas brindadas, que abra con ellas una puerta hacia lo desconocido. Basten algunas citas entre la cantidad de textos explicativos:

¿Qué le importaba a Van Gogh tu admiración? Lo que quería era tu complicidad, que trataras de mirar como él estaba mirando con los ojos desollados por un fuego heracliteano... y ha aprendido a mirar como él hacia la apertura infinita que espera y reclama. ${ }^{1}$ Intentar en cambio un texto que no agarre al lector pero que lo vuelva obligadamente cómplice al murmurarle, por debajo del desarrollo convencional, otros rumbos más esotéricos. Escritura demótica para el lector hembra (que por lo demás no pasará de las primeras páginas rudamente perdido y escandalizado, maldiciendo lo que le costó el libro) con un vago reverso de escritura hierática. ${ }^{2}$

El lector cómplice entra así en un juego trascendente en el que unas normas fijadas apenas si entorpecen el uso de su libertad plenaria. De tal modo entramos en ese juego que hasta nos sobrecoge, al escribir

I La vuelta al día en ocbenta mundos. (México-Buenos Aires: Siglo Veintiuno Editores, 1967), P. 208 .

2 Rayuela. (Cuba: Casa de las Américas, 1969), p. 466. 
sobre Cortázar, la sospecha temerosa de estarnos convirtiendo, a pesar nuestro, en uno de sus personajes. Y la seguridad poco confortadora de que esta anodina tarea de la crítica nos pone más cerca de las famas y las esperanzas, nostálgicas siempre del orden y de la claridad, que de los cronopios, imprevisiblemente libres.

Cortázar puede proponernos el juego de nuestra libertad porque su obra coincide, en temas y estructura, con una interpretación abierta del mundo. El mundo repite en apretados microcosmos individuales el dibujo de la totalidad objetiva. Conocer es armar, como desde un caleidoscopio, de acuerdo con nuestro centro personal, los elementos de la realidad; cada una de las móntadas refleja, sin embargo, el universo. La relación entre el punto de vista relativo y la visión más amplia y absoluta está claramente representada en Cortázar por la figura simbólica del mandiala. Ese círculo, o cuadrado a veces, o cuadrados encapsulados en el círculo, o círculo dividido en cuatro o en múltiplos de cuatro, con todas sus posibles variaciones significativas, participa en las religiones orientales de la misma ambivalencia que Cortázar le reconoce: es un símbolo objetivo del universo, en que se encierran todas las posibles fuerzas, mal y bien, tierra y cielo, individuo y cosmos y es, al mismo tiempo, en su uso ritual, un camino que permite acceder psicológicamente desde un centro personal a la totalidad objetiva. El "shaman" frente al mandala escoge como centro cualquiera de sus figurillas simbólicas y desde allí atisba la totalidad; puede cambiar de centro: cada nuevo desplazamiento le permite una apreciación siempre distinta, y en el fondo siempre igual, de la unidad totalizadora. Cortázar percibe el mantala en el plano de la ciudad de París, visto desde el Arco del Triunfo: "París es un centro, una mandala que hay que recorrer sin dialécticas." 3 No es casual: el ejemplo aparece ya en la obra de Jung y sus discípulos. Peto también se puede acceder a un centro modificador de la perspectiva por un simple proceso psicológico, cuando un detalle casi no observado o una sensación inesperada vuelven a agitar los elementos del prisma para componer una nueva imagen:

Está la noche en Delfos en que sentí lo luminoso y no supe morir, es decir nacer; están las altas hotas de Micenas, la escalinata de Faistos, y las minucias que la araña guarda en cumplimiento de una figura que se nos escapa, el dibujo de un mediocre fragmento de

3 Ibid., p. 50.

4 Carl G. Jung [y otros], Man and bis Symbols. (New York: Doubleday and Company, 1964), P. 243. Véase además las referencias al mandala, especialmente pp. $213-217$ y $242-245$. 
mosaico en el puerto romano de Delos, el perfume de un helado en una calleja de Placca. ${ }^{5}$

El escritor y sus personajes, y los lectores que acepten la propuesta del juego, vivirán a la búsqueda de nuevos centros orientadores. Caminar sobre las calles de París, recorrer pasillos, abrir una ventana o una puerta, divagar distraidamente, se convierten asi en una prodigiosa aventura, tan simple en su cotidianeidad como maravillosa en sus posibilidades: "Ando por una enorme pieza con pisos de baldosas y una de esas baldosas es el punto exacto en que debería pararme para que todo se ordenara en su justa perspectiva".

En Buenos Aires, cuyo plano no es un mandala, la rayuela trazada en la acera de la casa en que viven Oliveira y Traveler o en el patio de la clínica, o reproducida en el diseño de los jardines y de los pisos embaldosados, participa del mismo dibujo simbólico:?

... doblar una pierna y empujar un tejo de la primera a la segunda casilla, de la segunda a la tercera... y asomar una noche en Buenos Aires para repetir en la rayuela la imagen misma de lo que acababan de alcanzar, la última casilla, el centro del mandala, el Ygdrassil vertiginoso por donde se salía a una playa abierta, a una extensión sin límites, al mundo debajo de los párpados que los ojos vueltos hacia adentro reconocían y acataban. ${ }^{8}$

La propia obra literaria es un mandala: "Escribir es dibujar mi mandala y a la vez recorrerlo, inventar la purificación purificándose; tarea de pobre shaman blanco con calzoncillos de nylon."

El lector reproduce así el mismo ritual de conocimiento que el escritor y sus personajes. Busca, simple busca, sin solución definitiva. Cortázar no nos impone dogmáticamente su idea de la realidad sino que nos proporciona un método para descubrirla. Deja abierta siempre las posibilidades para otras relaciones que se suceden en un orden mágico imposible de reducir a una interpretación definitiva. Cada nuevo centro, cada combinación desatan infinitas coordenadas que se agrupan en miles de insospechadas asociaciones. Como la simple jugada del alfil, que cambia las tensiones del tablero, o un momento del juego de River Plate que

- La vuelta al dia..., p. 61.

- Rayuela, p. 96.

7 Rayuela iba a Ilamarse Mandala. Ver Juan Loveluck, "Aproximación a Rayuela", Revista Iberoamericana, 65, enero-abril de 1968, p. 89.

8 Rayuela, p. 385.

Ibid., p. 472. 
provoca una asociación de ideas en :un físico de Roma, y así hasta el infinito. ${ }^{10}$

Cortázar propone al lector una tarea estructuralizadora de la realidad en que cada momento coagula un cierre transitorio del que se desprende una nueva apertura tendiente a un nuevo cierre $y$ así en cadena indefinida. Como la cadena de las reacciones atómicas. Sirve como ejemplo su propia obra: cada nuevo libro deshace la estructura del anterior $y$ propone una nueva estructura transitoria. El lector bembra se impacienta ante esta constante provocación de actividad.

\section{la Realidad. De Este Lado}

Es que el lector bembra acepta la visión ordenada de la realidad según la transmite el pensamiento occidental desde milenios. Cortázar es claramente explícito. El hombre equivocó la ruta al tomar el camino del racionalismo. Dios le advirtió atinadamente sobre el riesgo de comer la fruta del árbol de la ciencia. La razón parcializa, falsea la realidad: "Apenas intente analizar, meteré todo en la consabida fiambrera rectangular y lo falseaté insanablemente."11 Toda lógica, todo orden, toda geometría, escamotean la realidad auténtica:

No quiero escribir sobre Rocamadour, por lo menos hoy, necesitaría tanto acercarme a mí mismo, dejar caer todo eso que nos separa del centro. Acabo siempre aludiendo al centro sin la menor garantía de saber lo que digo; cedo a la trampa fácil de la geometría con que pretendemos ordenar nuestra vida de occidentales. Eje, centro, tazón de ser, Omphalos, nombres de la nostalgia indoeuropea... A veces me convenzo de que la estupidez se llama triángulo, de que ocho por ocho es la locura o un perro. ${ }^{12}$

El aceptar un centro puede tener mayor validez estética; pero es un engaño. No hay centro, sino ondulación de la materia. ${ }^{13}$ Esa busca del conocimiento tiene por eso una dimensión heroica. No aceptar los centros ilusorios, rebelarse contra las conformidades momentáneas.

El buen burgués es un conformista. Para él "el deber, lo moral lo inmoral y lo amoral, la justicia, la caridad, lo europeo y lo americano,

10 La vuelta al día. ., p. 52.

11 62. Modelo para armar (Buenos Aires: Sudamericana, 1969), p. 11.

12 Rayuela, pp. 22-23.

19 Ibid., p. 290. 
el día y la noche, las esposas, las novias y las amigas, el ejército y la banca, la bandera y el oro yanqui o moscovita, el arte abstracto y la batalla de Caseros", son verdades evidentes y reales como si fueran dientes o pelos. Todo debe seguir igual: la razón guía hacia la verdad, la ciencia ayuda, el atte impone su calidad estética. Cortázar ironiza:

¿Qué punto de comparación tenés para creer que nos ha ido bien? ¿Por qué tenemos que inventar el Edén, vivir sumidos en ta nostalgia del paraíso perdido, fabricar utopías, proponernos un futuro? Si una lombriz pudiera pensar, pensaría que no le ha ido tan mal. El hombre se agarra de la ciencia como de eso que llaman áncora de salvación y que jamás he sabido bien lo que es: La razón segrega a través del lenguaje una arquitectura satisfactoria, como la preciosa, rítmica composición de los cuadros renacentistas, y nos planta en su centro. A pesar de toda su curiosidad y su insatisfacción, la ciencia, es decir la razón, empieza por tranquilizarnos. "Estás aquí, en esta pieza, con tus amigos, frente a esa lámpara. No te asustes, todo va muy bien. ¡A Ahora veamos! ¿Cuál será la naturależa de ese fenómeno luminoso? ¿Te has enterado de lo que es el uranio enriquecido? ¿Te gustan los isótopos, sabias que ya transmutamos el plomo en oro?" Todo muy incitante, muy vertiginoso, pero siempre a partir del sillón donde estamos cómodamente sentados. ${ }^{14}$

El buen burgués vive en un territorio, lugar propio y confortable, centro inamovible. En Rayuela, Traveler es el hombre del territorio, tiene mujer y empleo y no ha viajado nunca, a pesar de su nombre. Se opone a Oliveira por su conformismo esencial: "En el fondo, Traveler era lo que él hubiera podido ser con un poco menos de maldita imaginación; era el hombre del tertiorio, el incurable error de la especie descaminada, pero cuánta hermosura en el error y en los cinco mil años de territorio falso y precario."15

Hemos entrado ahora en una nueva era: la era de la cibernética. Lo terrible es que con su ciencia, sus satélites artificiales, sus hormonas y reactores atómicos, el hombre moderno creará no una pesadilla de Orwell o de Huxley, sino un mundo plastificado, delicioso. Hasta los escapes

\footnotetext{
14 Ibid., :pp. 97; 197-198.

15 Ibid., p. 414. "Pero vos que estás en armonía con el territorio no querés entender este ir $y$ venir, doy un empujón y me pasa algo, entonces cinco mil años de genes echados a perder me tiran para atrás y recaigo en el territorio, chapaleo dos semanas, dos años, quince años". Rayuela, p. 412.
} 
de ese mundo están ya planificados: "Se planifican los escapes, se los tecnologiza, se los arma con el Modulor o con la regla de Nylon. Hay imbéciles que siguen creyendo que la borrachera es un método, o la mescalina, o la homosexualidad, cualquier cosa magnífica e inane en 'si pero estúpidamente exaltada a sistema, a clave del reino."16 Por último, el buen burgués posee una expresión estética caracterizada por el escamoteo de los problemas que le conciernen. Así lo piensa Morelli al refetirse al lector hembra que no quiere problemas sino soluciones o falsos problemas ajenos.

Uno de los rasgos distintivos de la literatura de Cortázar es la parodia del comportamiento burgués. A veces habla de ello directamente; pero sobre todo utiliza las mecánicas de ese comportamiento como recurso irónico: imita los sueltos periodísticos, las instrucciones que acompañan a los artefactos de uso común, los manuales técnicos, los modos de relación social. Uno de los encantos de sus relatos breves consiste precisamente en que lo extraordinatio se inserta en una norma perfectamente conocida e impecablemente descripta. ${ }^{17}$ Se levanta un catafalco como se construye una casa o una escultura, la organización de un velorio o del reparto de globos y golosinas en el Correo no difieren de las técnicas de la organización de empresas. Hasta el vómito de conejos blancos reproduce el mecanismo de nuestra fisiología humana. Cortázar es un maestro de la observación y del pastiche. A veces sustituye la parodia por el directo collage, copiando de otros textos, ilustrando. Las famas y las es. peranzas no. reflejan totalmente el comportamiento burgués, ${ }^{18}$ pero si algunos caracteres distintivos: "Esas cosas quedan para las famas, $y$ también las esperanzas, que se ocupan de recoger las crónicas, establecer las fechas, y encuadernarlo todo con tafilete y lomo de seda." 19

\section{EL Otro LADo}

Del otro lado de nuestra realidad hay un territorio explorable. Cortázar lo diferencia de la realidad habitual con el nombre de zona. Sólo en actitud mediúmnica podemos atisbar ese otro lado. Pero no se trata

\footnotetext{
16 Rayuela, pp. 449.450.

17 Véase Manuel Durán, "Julio Cortázar y su pequeño mundo de cronopios y famas", Revista Iberoamericana, 59, enero-junio de 1965. Reproducido en la selección antológica de estudios sobre Cortázar, La vuelta a Cortázar en nueve ensayos (Buénos Aires: Carlos Pérez, Editor, 1969), pp. 31-49. Aquí el apellido Durán, por error, aparece con d final.

18 Durán, art. cit., p. 42.

10 Le vuelta al día. ., p. 121.
} 
únicamente de la realidad objetiva. También nuestra psicología se abre al otro lado cuando abandonamos los controles racionales.

El simple hecho de esperar un ascensor nos trae el conocimiento de la zona donde alguien, o nosotros mismos, nos esperamos para cerrar el circuito:

... mientras por detrás, en alguna parte que forzosamente hay que situar y que la incertidumbre termina situando siempre detrás o en lo hondo, en todo caso en alguna región diferente de lo que está sucediendo ahí, hay que esperar crispada a que el ascensor llegue al piso donde la están esperando y que ella no ha marcado en el tablero del ascensor porque ese ascensor no tiene tablero, es un ascensor blanco y brillante completamente desnudo en el que ni siquiera se alcanza a reconcer la puerta una vez que distraídamente se ha cambiado de posición mientras se espera sosteniendo el paquete, el cordel amarillo que lastima los dedos. ${ }^{20}$

La visión de la zona completaría, de ser posible su conocimiento pleno, nuestra vida parcelada en la realidad. Basta un instantáneo corrimiento a un costado para ver, sin que sepamos por qué, nuestro ser parcelado, la sospecha de un más allá, donde nosotros mismos, en el resto de una realidad ignorada, nos esperamos inútilmente. ${ }^{21}$ Como en las imágenes de los sueños las figuras de Cortázar se alargan en un ademán despacioso proyectándose hacia ese otro lado que las atrae $y$ las rechaza al mismo tiempo. Son seres dramáticos que reconocen sus propios límites pero procuran derribarlos.

Ia actitud burguesa consiste en dar la espalda a la zona, no abrir la puerta hacia el otro lado, conformarse con el límite. La razón no sirve para determinar la zona; por el contrario, mata la posibilidad de reconocerla: "Y había más que eso, había la intersección, el acceso por las ilusiones a un plano, a una zona inimaginable que hubiera sido inútil pensar porque todo pensamiento lo destruía apenas procuraba cercarlo." 22

Toda comunicación humana se debate entre los límites y la zona; vale por ese aspecto fantasmal. El amor incita a tender hacia lo otro, hacia ese ámbito de complementación donde toda felicidad sería posible. Los amantes hacen gestos desesperados hacia un encuentro; a veces, sin éxito, sin posibilidad de comunicación profunda:

\footnotetext{
20 62. Modelo..., p. 139.

21 Rayuela, p. 477.

22 Ibid., pp. 11-12.
} 
Como no sabías disimular me dí cuenta enseguida de que para verte como yo quería era necesario empezar por cerrar los ojos, $y$. entonces primero cosas como estrellas amarillas (moviéndose en una jalea de terciopelo), luego saltos rojos del humor y de las horas, ingreso paulatino en un mundo-Maga que era la torpeza $y$ la confusión pero también helechos con la firma de la araña Klee, el circo Miró, los espejos de ceniza Vieira de Silva, un mundo donde te movías como un caballo de ajedrez que se moviera como una torte que se moviera como un alfil." ${ }^{23}$

En los momentos de exaltación amorosa la zona se vislumbra impen. sadamente. Luego es difícil repetir la experiencia. E imposible precisarla con palabras. Contarla, ponerla en orden, es someterla al esquema racional, es falsearla.

- Los amigos andan a la espera de esa comunión momentánea. En el juego de la comunicación, a veces entran en la zona, a veces se alejan de ella:

... todo lo que emerge en el que irónicamente piensa que en algún momento tendrá que ponerse a contar y que acaso Hélène no estará en la zona y no lo escuchará aunque en el fondo todo lo que él vaya a decir sea siempre Hélène... Pero también puede ocurrir que los otros estén en la zona como tantas otras veces, que la vida los envuelva y se oiga la tos de un guardián de museo mientras una mano busca lentamente la forma de una garganta. . .4

No interviene demasiado la voluntad; generalmente, circunstancias exteriores nos sacan de nuestros límites. El hombre sale entonces de su centro, se des-centra o ex-centra o des-coloca. Paradójicamente se siente ahora trás próximo al centro verdadero que aquellos que prefieren el eje de la vida cotidiana. Es una actividad tantálica, caracterizada por el esfuerzo, ese salir (o subir) para recaer constantemente en la realidad. El tejo de la rayuela, juego de colocación y descolocación, recuerda por momentos la piedra de Sísifo: "Llegar con la piedrita (¿cargar con su criz? Poco manejable este artefacto.)" 25

El contacto con la otra zona se logra a través de los buecos, las carencias, los intersticios de la realidad y de la lógica. Los maories han

\footnotetext{
23 Ibid, p. 13.

24 62. Modelo ..., p. 16.

is Rayuela, p. 259 .
} 
procurado establecer la categoría de los espacios intermedios. ${ }^{20}$ En un reciente libro sobre experiencias mágicas, la comunicación con el otro mundo se logra también a través de los buecos que deja entre sí la cadena sonora de la naturaleza y que nuestro oido habitualmente no percibe. ${ }^{27}$ En las novelas de Cortázar una puerta, una ventana que se abre, un pasillo, una bocanada de aire o de humo, adquieren inmediato valor simbólico: son la materialización de esos intersticios.

Ver hacia el otro lado implica un cierto entrenamiento. Oliveira de a la Maga lecciones de mirar y de ver: un modo de pararse en la calle, de espiar un zaguán donde no hay nada, de ver más allá un vislumbre verde, un resplandor; y de pasar seguidamente al gran patio abierto. Los huecos son carencias, ausencias de ser: "Veo lo que no soy. Por ejemplo (esto lo armo de vuelta pero sale de ahí) hay enormes zonas a las que no he llegado nunca, $y$ lo que no se ha conocido es lo que no se es." ${ }^{28}$ Por el lado de esas carencias se acerca lo desconocido: "Todo era menos, era signo menos, menos rellano, menos puerta, menos luz, menos cama, menos Maga... Sonaba todavía a hueco, a realmente no vivido." "Puedo saber mucho o vivir mucho en un sentido dado, pero entonces lo otro se arrima por el lado de mis carencias y me rasca la cabeza con su uña fría."29

La comunicación crea constantemente hueco, aperturas hacia el otro lado, que se van colmando vicariamente. También el arte, forma más alta de comunicación:

... terminar de colmar el maldito hueco echándole adentro la piedra de hule... saltarle encima con el martillo y el cincel como Hamlet tirándose al agujero que había sido. Ofelia, recortar la figura de Vercingetórix en la masa misma del antiguo hueco. ${ }^{30}$

La ausencia del amigo, o del ser amado, forma un enorme agujero, un hueco redondo y negro. Talita llena, por un instante, la inmensa carencia de la Maga, cuya desaparición provocó en Oliveira un dolorido hueco, una patética llaga. No es raro que los huecos nos permitan anular el tiempo, revivir en ellos el pasado y avizorar el futuro. Del hueco en el rumor gastronómico del Restaurante Polidor surge la coincidencia entre

26 La vuelta al dia..., pp. 65-66.

27 Carlos Castañeda, $A$ Separate Realisy (New York: Pocket Books, 1971). pp. 222-226.

28 Rayuela, p. 476.

29 Ibid., Pp. 573 y 478.

30 62. Modelo..., p. 85. 
un espejo del espacio $\mathrm{y}$ otro del tiempo. En el espejo ve el personaje un agujero negro, un embudo, que se traga el presente con repugnante gorgoteo. 31

Son esos huecos los que permiten la caleidoscópica reestructuración de la realidad..$^{32}$ Lo impensado, lo espontáneo, la circunstancia inesperada, el fluir del inconsciente, descubren de pronto el hueco de la realidad; surgen analogias, recuerdos, esperanzas; las cosas se ordenan de acuerdo con un nuevo centro, forman una constelación, un acorde, se aglutinan, se coagulan; luego se deshacen en parcelas hasta tanto otro hueco produzca un centro nuevo. ${ }^{33}$

La realidad y la zona están en constante conflicto. Se habla de agazapamientos, de zarpazos. A veces la intersección de los diferentes planos adquiere un sentido trágico: cuando un accidente, una declaración de guerra, provocan el choque brutal entre realidades diferentes. Los personajes de Cortázar viven el drama de esa bivalencia. No pueden conformarse gozosamente con la realidad, ni tampoco acceden de lleno a la zona entrevista. Como figuras del Greco, estiran sus contornos en un afán nunca cumplido, en un puro movimiento hacia afuera (o hacia adentro) que sólo resulta en angustia, en dolor de existir. El suicidio es un modo fácil de saltar, saltar desde el puente al tío, desde la ventana al patio, de la realidad a la otra zona.

En el pensamiento occidental, la otra zona ha sido también sometida a fórmulas racionales de aprehensión. Un ejemplo, los místicos. San Juan de la Cruz, cuyos yersos inserta Cortázar en su propia prosa, ha cuadriculado racionalmente la zona y haconvertido en proceso lógico el modo de acceder.

El escritor, como todo poeta, atisba los huecos de la realidad y nos incita a buscar los nuestros: "Iscribo por falencia, por descolocación, y como escribo desde un intersticio, estoy siempre invitando a que otros busquen los suyos y miren por ellos el jardín donde los árboles tienen frutos que son, por supuesto, piedras preciosas." ${ }^{44}$ Morelli procura escribir una novela de huecos para que el lector llene los espacios a su antojo. El lenguaje poético crea intersticios, vale como exorcismo, como fórmula de extrañamiento.

16id., pp. 26, 30, 71 y passim. nota.

32 Sobre la imagen del caleidoscopio en Rayuela, ver Loveluck, art. cit., p. 84,

33 62. Modelo..., passin.

34 La melta al dia..., p. 21. 


\section{Los Modos de Extrañamiento. El Juego}

Los momentos de mayor hondura en los personajes de Cortázar coinciden con su extrañamiento de la realidad. "De pronto Oliveira se extrañaba andando con la Maga." 35 Son instantes de enajenación más o menos dichosa que permiten entrever algo que podría ser un Paraíso. El personaje anda entonces por afuera de sus límites y sus actos se convierten en gestos vacíos, lentos mecánicos: "Se ha quedado como por fuera de lo que estaba por hacer, está perdida, mírala, pero mírala bien, fíjate cómo vuelve a tomar el piyama y se lo alcanza, quiere ayudar a ponérselo $\mathrm{y}$ es tan difícil como vestir a un muerto." 36

A veces, salir es sólo ponerse a caminar por las calles de París ("Y - me bastaba para salirme y andar por ahí donde me gusta andar cada vez que puedo... alejarme de la cuadticulada vida."s7) Pero son las circunstancias exteriores, una música, el amor, cualquier distracción -las distracciones tienen importante papel-, las que aislan la conciencia vigilante y permiten salir como en un rapto de inspiración o de mania: La Maga es uno de los caminos para extrañarse, la literatura otro, y también la ficca, la meditación "al soberano cuete." 38 La salida ocurre en cualquier momento, cuando estamos sentados en el WC y, sobre todo, entre muslos de mujeres, entre nubes de humo, a la mitad de una lectura. Sólo aquello que permite esa posibilidad de extrañamiento tiene valor. Oliveira arma estructuras con hilo, para que haya huecos, para que circule el aire entre ellos; gusta del espacio libre, de los libros, las mujeres y las obliga. ciones que permiten salida. Toda salida enriquece nuestra realidad:

Primeto eliminá eso de física y de metafísica que parecen las dos manivelas del fútbol de mesa. $\mathrm{Si}$ vos, en el momento en que le untás la manteca al pan (te recomiendo la de Isigny, que es la mejor) sos capaz de enlazar ese conjunto donde entran tu apetito, los ingredientes citados $y$ un cuchillo, con por ejemplo una frase de una sonata de Chopin o uno de esos recuerdos recurtentes que por algo son recurrentes, te darás cuenta de que al margen de las asociaciones analógicas se abre una segunda opción, la de entender el producto como realidad enriquecida en el sentido en que los físicos hablan del uranio o del plutonio enriquecido. Inmediatamente, si persistís, si todos tus actos-vida de esa hora $y$ de ese

35 Rayuela, p. 32 .

36 62. Modelo. ., p. 180.

37 La vitelta al'dia..., p. 106.

38 Rayuela, p. 350. 
día se arman dentro de esa tendencia a salirte de vos mismo, a enlazar con otras manifestaciones físicas o psíquicas, como ya lo sabían los románticos más visionarios, el resultado será que en las últimas etapas de esa secuencia llegarás a una especie de colmena porosa, de grandísima chimenea en lo real, apenas digas: ¡Qué bonita es esa rubia!, o te ates los cordones de los zapatos. Una praxis, che, una praxis, seamos serios. ${ }^{39}$

En las crisis psicológicas, la salida se produce en forma abrupta. Entonces, según Cortázar, la realidad se precipita, abandonamos toda dialéctica, le soltamos la cadena al perro, actuamos con piedra libre para cualquier cosa. Lejos de ser escandalosas, que es como la gente las vive, esas crisis nos sacan del absurdo de un mundo ordenado y en calma; nos apartan del camino racional: "Pero esas crisis son como mostraciones metafísicas, che, un estado que quizá, si no hubiéramos agarrado por la vía de la razón, sería el estado natural del pitecantropo erecto." 40 Porque el absurdo no está en esos extrañamientos sino en la cotidianeidad que dejamos de lado; el absurdo es la costumbre, la falta de excepciones en el orden. A Gregorovius le ha interesado la siguiente nota de Morelli:

Internarse en una realidad o un modo posible de realidad, y sentir cómo aquello que en una primera instancia le parecía el absurdo más desaforado, llega a valer, a articularse con otras normas absurdas o no, hasta que el tejido divergente (con relación al dibujo estereotipado de cada dia) surge y se define un dibujo coherente que sólo por comparación temerosa con aquél parecerá insensato 0 delirante o incomprensible. ${ }^{41}$

Una vez extrañado el personaje percibe los huecos y en ellos recónditas galerías, pasajes, laberintos sin fin. Los corredores, los pasillos, reales se transforman en figuraciones simbólicas:

Atravesar la plaza desierta, acercarme al ministerio y buscar la puertecita lateral, observado alguna vez con recelo por indígenas trasnochadores que jamás podrán entrar así en lo que era de algún modo su propia casa, su ministerio, esa ruptura escandalosa de una realidad coherente $y$ finlandesa me sumia desde el comienzo en un

\footnotetext{
${ }^{39}$ La vuelta al dia. .., p. 63.

40 Raytzela, pp. 199-200.

41 Ibid., pp. 201, 512.
} 
estado propicio a lo que esperaba dentro, la lenta y furtiva divagación por corredores y escaleras y despachos vacios. ${ }^{12}$

Son laberintos de la vigilia. Otros son los que nos teje el sueño. No se trata de intercambiar una realidad por otra sino de complementarlas. El sueño fracasa en su fusión con la vigilia. Cortázar se aleja del surrealismo, a pesar de los puntos de contacto, porque se aleja del fácil onirismo. No son esos laberintos imágenes similares a las de la pintura surrealista, sino más bien visiones metafísicas, a la manera de la pintura de Chirico o de Carrá.

El juego es un laberinto de vigilia. Deberiamos poder diferenciar en español el juego entendido como normas fijas en que la libertad del jugador está condicionada (como ocurre con el ajedrez y con los juegos de mesa), del juego infantil, actividad casi libre, en que las normas se crean espontáneamente a medida que el proceso se desarrolla. Los juegos en Cortázar responden más a este segundo tipo. Son creaciones fantasiosas, como las de los niños que en Ultimo round juegan a ser sioux. Ejercicio de la plena libertad, estructuración libre de elementos. Así son los juegos en sus cuentos, en Rayuela, en 62. Modelo para armar. Cuando aparecen los otros juegos, como el ajedrez, Cortázar prefiere verlo como un ajedrez indio, en que el que gana se apodera del centro. El ajedrez sirve como símbolo en el universo de Borges, réplica de la realidad racionalizada, pero no en el mundo irracional de Cortázar.

Los personajes de Cortázar son niños grandes, neuróticos apegados a sus conductas infantiles. Como dice uno de ellos en Rayuela: "No somos adultos, Lucía. Es un mérito, pero se paga caro. Los chicos se tiran siempre de los pelos después de haber jugado." Juegos exasperantes y peligrosos. Jugar con muñecas, ya de grandes, es jugar al amor. ${ }^{48}$ Los juegos sociales son intentos desesperados de comunicación, de abritse huecos. Abundan, sobre todo en Rayzela, los juegos de palabras, como el encadenamiento de términos extraídos del diccionario, la composición de titulares de periódicos, de diálogos típicos, de palabras-balanza. El juego se hace serio cuando en un columpio entre dos departamentos juega Talita su indecisión amorosa o cuando Oliveira hace vertical la rayuela en la sala del hospicio y defiende con su propia vida el territorio conquistado. La vida, en fin es juego: "Los juegos idiotas, la vida."44 Los personajes juegan

42 La vusita al dia...., p. 76.

43 62. Modelo.... p. 143; Rayuela, p. 111.

44 62. Modelo..., p. 150. 
con la vida de otros: Talita se queja por ser objeto de un juego; la Maga resulta víctima del juego de Oliveira.

El juego es también un mandala, un modo de captar la totalidad:

Se entrara por una puerta abierta, a un jardín alegórico para los demás, como los mandalas son alegóricos para los demás, $y$ en ese jardín se pudiera cortar una flor y esa flor fuera la Maga o Babs, o Wong, pero explicados y explicándolos restituidos, fuera de sus figuras de Club, devueltos, salidos, asomados, a lo mejor todo eso no era más que una nostalgia del paraíso terrenal, un ideal de pureza, solamente que la purezá venía a ser un producto inevitable de la simplificación, vuela un alfil, vuelan las torres, salta el caballo, caen los peones, $y$ en medio del tableto inmensos como leones de antracita los reyes quedan flanqueados por lo más limpio, y final y puro del ejército, al amanecer se romperán las lanzas fatales, se sabrá la suerte, habrá paz.45

Jugar a la rayuela es tender hacia lo absoluto, conquistar el Cielo. Es un camino al kibbutz, a la posible felicidad.

\section{Los HEROES}

Los héroes en Cortázar son los inconformistas, los que no coinciden con la realidad de este lado, los que viven en un desorden, en una continua apertura a ese kibbutz ensoñado. Los que saben descubrir el otro lado de la costumbre, los irracionales, los ex-céntricos.

El mismo escritor se reconoce como excéntrico: "Vivo y escribo amenazado por esa lateralidad, por ese paralaje verdadero, por ese estar siempre un poco' más a la izquierda o más al fondo del lugar donde se debería estar para que todo cuajara satisfactoriamente en un día más de vida sin conflictos. Desde muy pequeño asumí con los dientes apretados esa condición que me dividía de mis amigos y a la vez los atraía hacia el raro, el diferente, el que metía el dedo en el ventilador:" Todo artista es para él un excéntrico. Los grandes poemas nacen de una extrañeza, se originan en una zona intersticial. El poeta escribe sobre lo que ve y siente en lugar de, al lado de, por debajo de, o en contra de lo que los demás, sin desplazamientos ni crítica, perciben habitualmente.46

45 Rayuela, p. 89.

16 La vuelta al dia..., pp. 22-24. 
También los locos ven las cosas desde un intersticio. No los locos definitivos, porque esos suplantan una realidad con otra, sino los fronterizos, los que se van de la realidad, los pitntados. Francia es un pais de piantados. Cortázar recoge los nombres de algunos que conoció, como Musitani o el inefable Ceferino, que sabe encontrar inesperadas relaciones y rompe así la "dura costra mental." Junto a los locos, los criminales. Los chicos criminales de los Estados Unidos sacuden el sistema. ${ }^{47}$

Otros seres fronterizos integran la galería de excéntricos. Los indecisos, como Hamlet (" $" N o s$ vengamos Hamlet, o tranquilamente chippendale, zapatillas y un buen fuego?"48), los rebeldes que rechazan toda idea recibida, toda estructura gregaria. Los humoristas.99

La denominación de cronopios los unifica. Los cronopios quiebran la estructura racional de Occidente:

El poeta, el pintor y a veces el loco. Esa reconciliación con un mundo del que nos separa un aberrante dualismo de raíz occidental, y que el Oriente anula en sistemas y expresiones que sólo de lejos y deformadamente nos alcanza, puede apenas sospecharse a través de vagas obras, de taros destinos ajenos, y más excepcionalmente en arrimos de nuestra propia búsqueda. ${ }^{50}$

Los cronopios no han renunciado a la visión juvenil como precio de la visión adulta; no coinciden del todo con cualquiera de las estructuras. Son pura libertad, como Louis Armstrong, ese "enormísimo cronopio." 51

En el campo del arte hay cronopios distinguidos. Armstrong, en la música. En el terreno de la plástica, Klee, que abre la puerta hacia el otro lado en oposición al realismo ingenuo de un Tiziano y a la cuadrilación de lo absoluto de un Mondrian. Cortázar califica como "grandísimo cronopio a Nijinsky, que descubrió columpios en el aire, escaleras que llevan a la alegria ${ }^{52}$ En la literatura, Tristán Tzara es un cronopio. Y André Bretón "que para su desgracia no fue lo bastante

\footnotetext{
47 Rayuela, p. 597. En las obras posteriores a Rayuela aparecen continua. mente referencias a locos o criminales; especialmente en La vuelta al dia. $L, y$ Ultimo round. Véase el poema de La vuelta al disa..., p. 57.

48 Rayuela, p. 28.

49 La vuelia al dia..., p. 21; Rayuela, p. 456.

50 La vuelia al dia.. ., p. 207.

51 Ibid., pp. 21 ; 122.

32 Sobre Klee y Mondrián, Rayuela, pp. 47-48; sobre Tiziano, "Instrucciones para entender tres pinturas famosas", en Historias de cronopios $y$ de famas (Buenos Aires: Ediciones Minotauro, 1962), pp. 18-19. "Nijinsky", en La vuelta al dia.., p. 121.
} 
pidntado, se contuvo al borde mismo de Nadja (iy qué borde, qué lección de abismo!").$^{53}$

El mismo Cortázar es un cronopio. Gran cronopio. Sabe hacer de su arte un gesto de vida. Como los dadaístas, como Dalí. Concibe la literatura no como escamoteo sino como fusión etótica y dadora del ser. ${ }^{54}$.

\section{El Arte Como Estructura Abierta}

El arte abre huecos hacia el otro lado, inventa lugares de revelación y de encuentro. Para que ello sea posible, la estructura de la obra debe ser abierta.

Un tipo de arte abierto es para Cortázar la música de jatzz: "Sucede además que por el jazz salgo siempre a lo abierto, me libro del cangrejo de lo idéntico para ganar esponja y simultaneidad porosa, una participación que en esta noche de Lester era un ir y venir de pedazos de estrellas, de anagramas y palindromas..." Los músicos de jazz actúan como intercesores, como Santos que muestran el cielo con el dedo, indicando el otro lado de la realidad. ${ }^{55}$

Los bappenings constituyen otro ejemplo de arte abierto. Se oponen a los valores de permanencia, de progreso, de humanismo, de cultura según los imaginan los bien pensantes; y por eso constituyen una actividad resistida por la policía. "Un happening es por lo menos un agujero en el presente; bastaría mirar por esos huecos para entrever algo menos insoportable que todo lo que cotidianamente soportamos." 56

En la literatura, Cortázar valora también aquellos géneros que facilitan la apertura. Juan Loveluck ha indicado la relación de su obra con la teoría de Umberto Ecco. ${ }^{57}$ La literatura fantástica se caracteriza para Cortázar por su tendencia a establecer un nuevo orden posible, una nueva variante del mandala, "un orden que puede usarnos en cualquier momento para uno de sus mosaicos." Es literatura abierta:

No se tenderá jamás a una conclusión porque nada concluye ni nada empieza en un sistema del que sólo se poseen coordenadas inmediatas. Alguna vez he podido temer que el funcionamiento de lo fantástico fuese todavia más férreo que la causalidad física; no

${ }^{53}$ La vuelia al dia..., pp. 53 y 170.

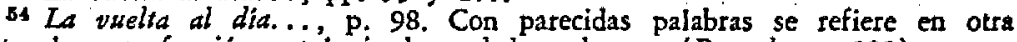
parte al amor, función ontologizadora, dadora de ser. (Rayuela, p. 120),

${ }^{55}$ Rayuela, p. 61. La vuelisa al dia..., p. 7.

so La vuslta al dia..., pp. 118-119.

57 art. cit., Pp. 88-89. 
comprendia que estaba frente a aplicaciones particulares del sistema, que por su fuerza excepcional daban la impresión de la fatalidad, de un calvinismo de lo sobrenatural. Luego he ido viendo que esas instancias aplastantes de lo fantástico reverberan de virtualidades prácticamente inconcebibles: la práctica ayuda, el estudio de los llamados azares va ampliando las bandas del billar, las piezas del ajedrez, hasta el límite personal más allá del cual sólo tendrán acceso otros poderes que los nuestros. No hay un fantástico cerrado, porque lo que de él alcanzamos a conocer es siempre una parte y por eso lo creemos fantástico.s8

El relato fantástico parcializa la visión del otro lado, pero propone un nuevo orden alejado de la realidad cotidiana. Es lógico que Cortázar no nos permita separar sus cuentos fantásticos de la primera época de sus obras posteriores. Define sus cuentos como "aperturas sobre el extrañamiento, instancias de una descolocación". Son momentos de una misma actividad impregnada de idéntico sentido, de la misma constante lücida:

Me aburre argumentar a posteriori que a lo largo de esa dialéctica mágica un hombre niño está luchando para tematar el juego de una vida: que si, que no, que en esta mano está. Porque un juego, bien mirado, ¿no es un proceso que parte de una descolocación para llegar a una colocación, a un emplazamiento - gol, jaque mate, piedra libre? ¿No es el cumplimiento de una ceremonia que marcha hacia la fijación final que le corona? ${ }^{50}$

Literatura como juego. Cortázar sabe que "los comisarios de turno" le reprocharán esa actitud lúdica. Los hombres racionales - dice- aceptan cualquier juego intelectual o sentimental, al modo de los ajedreces de Proust y de Joyce, siempre que las piezas y. las estrategias sean conocidas; pero rechazan la propuesta de "un juego nuevo para conocer otros territorios".60

Juego no sólo en cuanto a la concepción sino también en cuanto a la estructura. El juego combinatorio de Rayzela es todavía de sustitución o intercambio; pero en 62. Modelo para armar se trata ya de un juego libre. Se le dan al lector las piezas complementarias de un rompecabezas para que con ellas atme la figura principal, una figura además que será

\footnotetext{
58 La vuelta al dia..... pp. 44-46.

so Ibid., p. 21.

60 1bid., pp. 142-143.
} 
distinta a cada nuevo armado. En el sentido de la estructura, 62. Modelo para armar es una de las novelas más ambiciosas escritas en los últimos años. Se ha logrado una novela de total apertura, sin construcción sis. temática de caracteres, de situaciones. Historia, en fin, de desencuentros y de búsquedas. ${ }^{\text {G1 }}$

Cortázar tropieza con un inconveniente. No le basta la abolición de las categorías de tiempo y de espacio, ya demasiado disueltas en la novela contemporánea. Debe atacar de raíz el principio de causalidad; tanto en el nivel de la escritura como en el del sentido. No lo logra del todo, porque aún la libre analogía $o$ asociación responde a un elemento unificador. Opera lo que él mismo llama la causalidad afectiva, que hace que las cosas se aglutinen en nuestro propio centro. Pero pretende dar al lector los elementos en bruto con el simple ordenamiento causal transitorio que el escritor no puede eliminar del todo, pero que pueda ser reemplazado fácilmente por la causalidad afectiva del lector. La novela ha dejado de ser novela, se ha convertido en un instrumento, un revolvedor. Es acción, no novela. Es literatura agresiva, impositiva de conductas, irritante en el buen sentido del tétmino.

Ese principio activo en la novela cortaziana explica lo que hay en ella de revolucionario. Si Rayuela es para Cortázar una denuncia del establishment es por la oposición de su mundo al mundo racionalista, sistemático, de la burgueșía occidental. Novela revolucionaria, a pesar de su sentimentalismo demorado, de los mitos nacionales, de la actitud antidialéctica, de la falta del concepto de clases. A Cortázar no se lo puede prohibir; habria que cerrarlo.

El lector resulta el verdadero protagonista de esta aventura literaria. "Por lo que me toca me pregunto si alguna vez conseguiré en hacer sentir que el verdadero y único personaje que me interesa es el lector, en la medida en que algo de lo que escribo debería contribuir a mutarlo, a desplazarlo, a extrañarlo, a enajenarlo..."62

Se trata tan sólo de abrir la puerta para que el lector realice una experiencia de libertad. Ademán libertario. Cortázar confía en la posibilidad humana de organizar órdenes nuevos a partir de la libertad absoluta. No es extraño que recoja los grafitos de la revolución libertaria de mayo. Abrir la puerta a la libertad. Primero, en el nivel de la escritura: "Estamos forzados a crearnos una lengua que primero deje atrás a Don

61 Ver el capitulo 62 de Rayuela; 62. Modelo..., p. 7 y Oltimo round, p. 106 y sigts.

62 Rayuela, pP. 512-513. 
Ramiro y otras momias de vendaje hispánico, que vuelva a descubrir el español que dio a Quevedo o Cervantes y que nos dio Martín Fierro y Recuerdos de Provincia, que sepa inventar, que sepa abrit la puerta para ir a jugar." $Y$ después, o simultáneamente, en el nivel del sentido: "Detrás de todo eso (siempre es detrás, hay que convencerse de que es la idea clave del pensamiento moderno), el Paraíso, el otro mundo, la inocencia hollada que oscuramente se busca llorando, la tierra de Hurqlye. De una manera u otra todos la buscan, todos quieren abrir la puerta para ir a jugar." 63

RUBÉN BENÍTEZ

University of California. Los Angeles.

6s La vuelsa al día..., p. 100; Rayuela, p. 446. 
